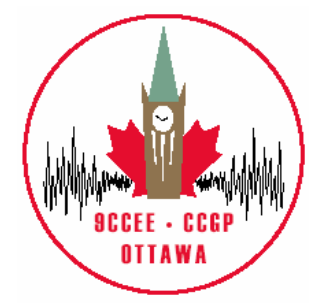

Ninth Canadian Conference on Earthquake Engineering Ottawa, Ontario, Canada 26-29 June 2007

\title{
STRONG MOTION SEISMOGRAPH NETWORKS IN CANADA
}

\author{
J.F. Cassidy ${ }^{1}$, A. Rosenberger ${ }^{1}$, G.C. Rogers ${ }^{1}$, T.E. Little ${ }^{2}$, J. Toth ${ }^{3}$, J. Adams ${ }^{4}$, P. Munro ${ }^{4}$, \\ S. Huffmann ${ }^{5}$, J.-R. Pierre ${ }^{6}$, H. Asmis ${ }^{7}$ and G. Pernica ${ }^{8}$
}

\begin{abstract}
Strong motion monitoring in Canada has undergone significant changes in recent years. Most analogue, non-communicating instruments have been replaced with modern digital instruments that provide information in real-time. Dense networks are being deployed in the urban centres of southwest British Columbia to provide shaking parameters and "shake maps" immediately after an earthquake. Monitoring of critical infrastructure, including bridges, dam sites and transmission facilities is increasing. This article documents the current state of strong motion monitoring across Canada, and summarises the data sets that are currently available. As of 2007, the Geological Survey of Canada operates 97 strong motion instruments (all Internet Acclerometers or IA's) in western Canada, most of which are deployed in the urban centres of high seismic hazard in southwest British Columbia. BC Hydro has 39 strong motion instruments at dam sites across BC. More than half of these are analogue SMA-1's, and are scheduled to be replaced by digital instruments within 2-3 years. BC Transmission Corporation owns 23 instruments (SSA-2's and ETNA's) installed at major substations and terminal stations across southwest BC. Other strong motion instruments in western Canada are owned by utilities or transportation organisations (BC Ministry of Transportation (MoT) has deployed 17 instruments to monitor lifeline bridges and a tunnel). In eastern Canada, the GSC operates a network of 26 strong motion instruments in the active Charlevoix zone, and 11 instruments in greater Ottawa. Hydro-Québec operates instruments at 12 dams and substations. Gaz Metropolitain operates an instrument at its Montreal LNG plant and New Brunswick Power operates an instrument at the Point Lepreau nuclear station. During the past six years, nearly 700 accelerograms have been recorded across Canada. Most of the records represent weak motion (PGA less than $5 \% \mathrm{~g}$ ), nonetheless, they are useful for evaluating local site response, which in turn may be valuable to engineers evaluating strong ground shaking during future earthquakes.
\end{abstract}

\footnotetext{
${ }^{1}$ Research Scientist, Geological Survey of Canada, PO Box 6000, Sidney, BC, V8L 4B2

${ }^{2}$ Engineer, B.C. Hydro Engineering, 6911 Southpoint Drive - A02, Burnaby, BC V3N 4X8

${ }^{3}$ Engineer, BC Transmission Corporation, 1055 Dunsmuir Street, Vancouver, BC, V7X 1V5

${ }^{4}$ Research Scientist, Geological Survey of Canada, 7 Observatory Cr., Ottawa, ON K1A OY3

${ }^{5}$ Engineer, BC Ministry of Transportation, 4B - 940 Blanshard St., Victoria, BC V8W 3E6

${ }^{6}$ Engineer, DESTT, Hydro-Québec, TÉ, 800 de Maisonneuve Est, 19e étage, Montréal, QC H2L 4M8

${ }^{7}$ Engineer, Ontario Power Generation, 700 University Avenue, Toronto, ON, M5G 1X6

${ }^{8}$ Senior Research Officer, National Research Council of Canada, 1200 Montreal Road, Ottawa, ON K1A 0R6
} 


\section{Introduction}

The purpose of this paper is to give a brief overview of the strong motion networks in Canada as they were at the beginning of 2007 . For details of the history of strong motion instrument deployment in Canada see Milne and Rogers, (1971), Rogers (1976), Rainer and Luctar, (1983), Weichert and Munro (1987), and Rogers et al. (1999). Since the last review by Rogers et al. (1999) the number of instruments deployed has (once again) nearly doubled and now the vast majority of instruments are digital with data availability in real-time. These modern digital instruments provide high data quality even near their limit of resolution and have adjustable triggers, which means the trigger levels can be optimized based on the local site conditions. The largest networks are the "Internet Accelerometer" network (see accompanying paper by Rosenberger et al. (this volume) operated by the Geological Survey of Canada (134 instruments), BC Hydro and BC Transmission Corporation (62 instruments) and Hydro-Québec (27 instruments) with most of the instruments in the earthquake prone areas of British Columbia and Quebec. A summary of instruments and owners is provided in Table 1.

\section{Western Canada}

\section{Geological Survey of Canada}

The GSC's strong motion network in western Canada has undergone a complete upgrade since 2001. Currently (2007), the strong motion network consists entirely of internet accelerometers (IA's). These are a new, GSC-developed strong-motion instrument that is permanently connected to the internet and records data continuously, rather than in "triggered mode". IA's also continuously compute a set of parameters which characterise the intensity of shaking and actively report those values whenever ground shaking exceeds certain levels to the GSC's data centres. Waveform data can be retrieved from an instrument at any time over the internet. For more details of the IA, see the article by Rosenberger et al. (this volume). The GSC network in western Canada (Figure 1-3) consists of 97 IA's (as well, IA data from BC MoT are collected and archived with these data). The purpose is to acquire strong ground motion records in and near urban areas and to define strong ground motion attenuation relationships for western Canada. There is also a focus on acquiring ground motion on the deep soft soils of the Fraser River delta just south of Vancouver. Instruments are deployed mostly in schools, surface vaults or small buildings (for internet access) to be as close to free field conditions as possible. There are currently no strong motion instruments operating in the Queen Charlotte Island region, or in the seismically active regions of northern Canada.

\section{BC Hydro and BC Transmission Corporation}

BC Hydro (BCH) and BC Transmission Corporation (BCTC) are Provincial Crown Corporations responsible for producing and delivering electricity to most of British Columbia. The two corporations operate strong motion instruments at key hydroelectric dams and electric system facilities (Figures 1-3). These instruments were installed as part of the permanent monitoring of important dams, to verify design assumptions about the dynamic behaviour of structures and foundations subjected to earthquakes, and to contribute to improving the strong motion data base for Western Canada.

Most of the $\mathrm{BCH}$ and BCTC SMAs were installed by BC Hydro in the period from the 1970s to the mid 1990s. In 2003, BCTC was created and given responsibility for planning, management and operation of BC Hydro's high-voltage transmission assets, including the SMAs installed at those facilities.

Currently, BC Hydro operates 39 SMAs at 17 dam sites around the province. Multiple instruments are often installed at one dam site in locations such as on foundation bedrock and on the top of the dam to evaluate amplification effects. The primary interest for monitoring dams is to record strong motions for post-earthquake back-analysis of dam performance. 


\section{Strong Motion Seismographs in Western Canada}

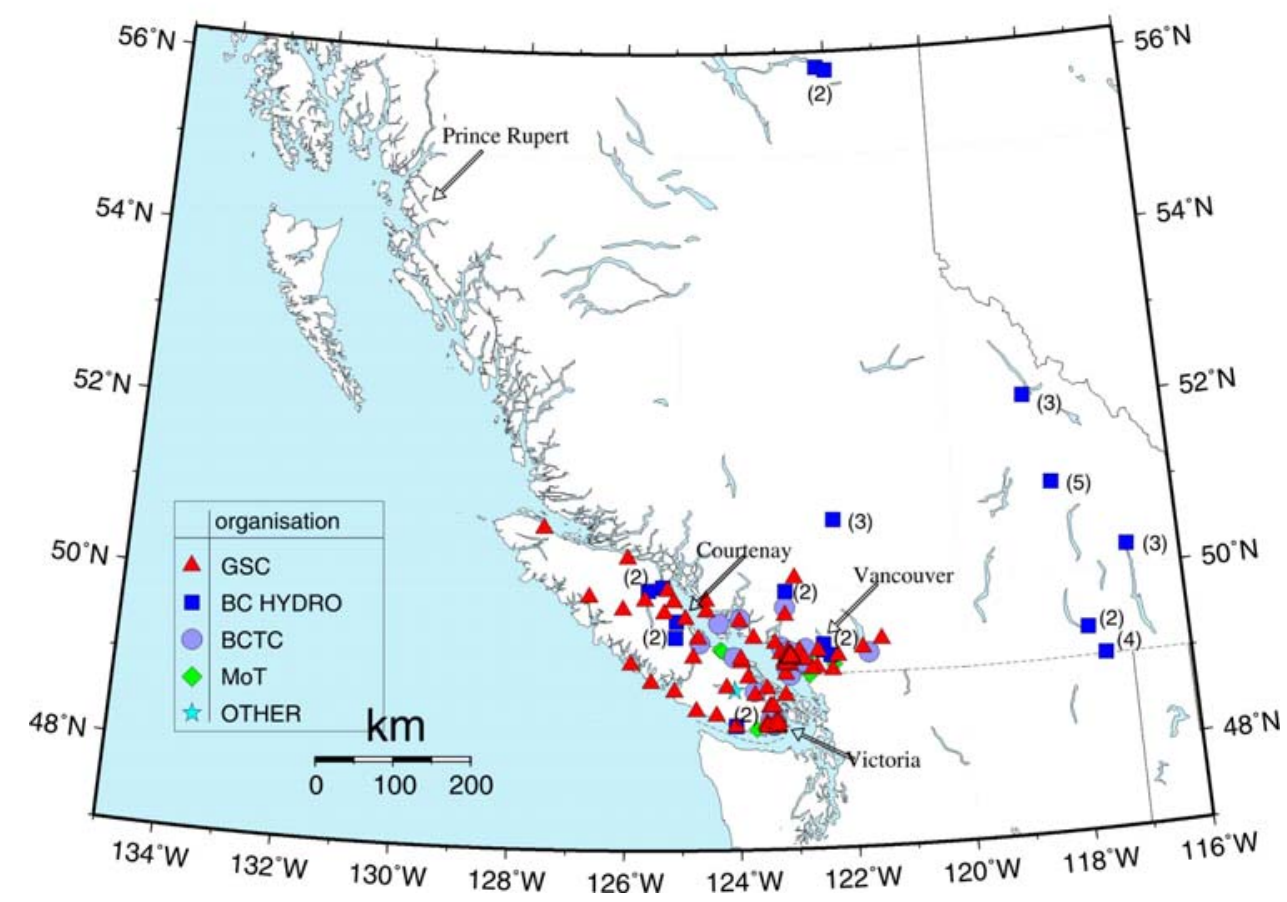

Figure 1. Strong motion seismographs in western Canada. Numbers in parantheses indicate the total number of strong motion seismographs at a site.

Strong Motion Seismographs in Southwest BC

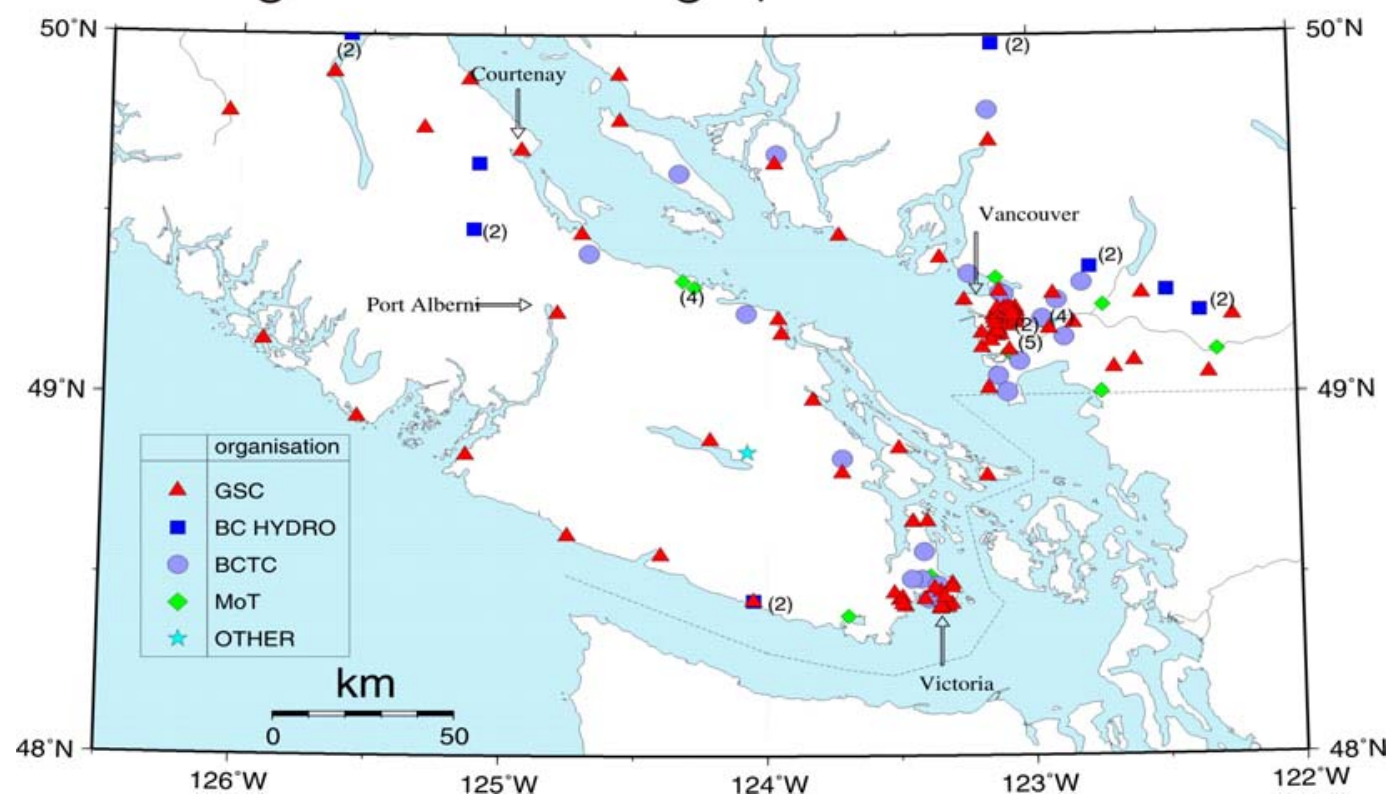

Figure 2. Strong motion seismographs in southwest BC. Numbers in parantheses indicate the total number of strong motion seismographs at a site. 


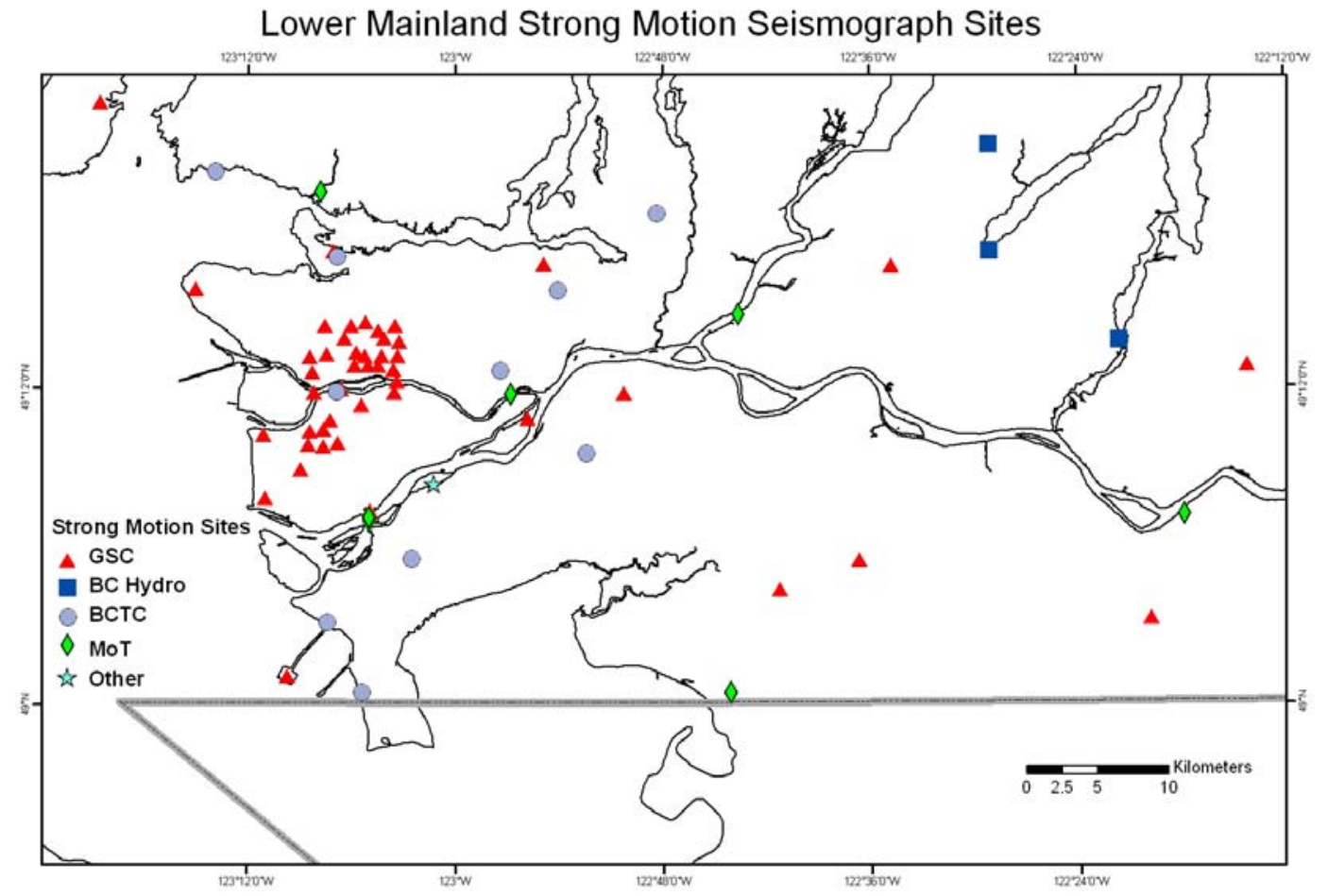

Figure 3. Strong motion seismographs in greater Vancouver.

Information for emergency response is not a major issue because dams are always inspected immediately following any earthquake felt at or near the dam, with or without site-specific information on the ground motion experienced. Twenty-eight of the $\mathrm{BCH}$ instruments are still the old analogue SMA-1s (1-g full scale, and all with a trigger threshold of $1.0 \% \mathrm{~g}$ ) which are essentially obsolete and nonmaintainable. Most of the other instruments are ETNAs (2-g full scale, with trigger thresholds of about $0.5 \% \mathrm{~g}$ ). The analogue instruments are scheduled to be replaced by digital instruments within 2 to 3 years. Internet accelerographs are currently being evaluated at 4 sites as one potential replacement instrument option. However for some remote dam sites, reliable internet access to the instrument is not yet readily available at acceptable cost. Some installations such as on top of dams in northern locations must also be able to cope with severe seasonal climatic ranges.

BC Transmission Corporation (BCTC) owns 23 SMAs, all SSA-2s and ETNAs, all in southwestern BC. All of these are $2-\mathrm{g}$ full scale, and are set to trigger at thresholds of either $0.4 \% \mathrm{~g}$ or $0.6 \% \mathrm{~g}$. Trigger thresholds are set as low as possible to allow recording of low-level ground motions, while avoiding false triggers due to traffic or other cultural vibrations.

Instruments are installed at major substations and terminal stations and have recorded a number of earthquakes (described in more detail later in this article) including the $2001 M_{W} 6.8$ Nisqually Washington and $2006 \mathrm{M}_{\mathrm{W}} 3.7$ Strait of Juan de Fuca earthquakes. The original purpose for installing these instruments was primarily for post-earthquake back-analysis of station performance, but in the future, reliable real-time warning capability could be of value to system operators.

One downhole SMA was installed at Kidd 2 Station to investigate near-surface amplification effects in the Fraser River Delta soils. That instrument failed several years ago and could not be recovered from the drill hole; there is no plan to replace it at this time. All of the other instruments are surface installations that continue to function well, although the SSA-2S are now getting old for digital instruments and replacement with a modern digital instrument will be considered within the next several years. $\mathrm{BCH}$ and BCTC continue to share any records obtained with the scientific and engineering communities in order to maximize the value of the records. The GSC has copies of all records obtained to date. 


\section{BC Ministry of Transportation}

The B.C. Ministry of Transportation (BC MoT), in collaboration with the University of British Columbia Department of Civil Engineering, and the GSC, operates 17 strong motion instruments at locations (including some key bridges and the Massey Tunnel beneath the Fraser river) in southwestern British Columbia. Six of these instruments are IA's (see: http://earthquakescanada.nrca.gc.ca/stnsdata Icnsn/sm/sm motbc e.php) with data archived with GSC data (described above). An additional ten IA's have been purchased and will be deployed along the Sea-to-Sky Highway north of Vancouver during 2007. Additional strong motion instruments (Geosig AH-63-DH shallow downhole instruments) will be deployed in Kelowna, BC and on the Pitt River Bridge, in the near future.

The main goal of this program is to obtain information about ground motions and structural responses of critical transportation links in southwestern British Columbia, for use in seismic design and the retrofit of highway structures. For details on the instrumentation at the Queensborough Bridge, Massey Tunnel, and French Creek Bridge, see Latendresse and Ventura (1997). Real time IA data are combined with GSC and data from other partners in order to produce shaking maps, and near-real-time estimates of ground shaking parameters useful for earthquake response.

\section{Other}

Terasen Gas (formerly BC gas) operates two strong motion instruments (GeoSig GSR-18) at the Tillbury Island LNG plant, just south of Vancouver.

\section{Eastern Canada}

\section{Geological Survey of Canada}

The GSC operates an eastern regional network of 26 instruments (many in the vicinity of the seismicallyactive Charlevoix region - see Figure 4) to gather near-field strong motion and to define strong ground motion attenuation relations for eastern Canada. Replacement of the $1 \mathrm{~g}$ SMA-1 instruments by $2 \mathrm{~g}$ ETNA accelerographs was started in the fall of 1998 and at present only one of the SMA-1 instruments remains in operation. Six of the ETNAs are co-located with the triaxial seismographs of the Charlevoix Local Telemetred Network.

Trigger thresholds vary between $1 \% \mathrm{~g}$ for the SMA-1 to $0.25 \% \mathrm{~g}$ for the ETNA's. Instruments are deployed mainly in surface bedrock vaults or in small buildings to be as close to free field conditions as possible. One (Baie St. Paul) is a soil site.

The GSC also operates a temporary prototype urban strong motion network in Ottawa. This consists of five ETNAs and six IAs. The first ETNAs were deployed in 2002 and the IA's were deployed starting in mid-2004. The instrument collocated with the Ottawa seismometer is on a pier on bedrock, while the remaining instruments are sited in basements of small buildings on a variety of soil conditions including some thick, soft soil sites. The Ottawa network has already produced some interesting earthquake records which demonstrate the nature and amount of soil amplification. The AuSable Forks earthquake (20020420) produced 18 accelerograms, 12 of the magnitude MW 5.0 mainshock and 6 of a M4.1 aftershock (Al-Khoubbi and Adams, 2004). The MW 4.7 Rivière-du-Loup (Grand-Portage) earthquake (20050306) produced 9 accelerograms, and the MW 4.0 Thurso earthquake (20060225) produced 21 accelerograms (Adams 2007, this volume). 


\section{Strong Motion Seismographs in Eastern Canada}

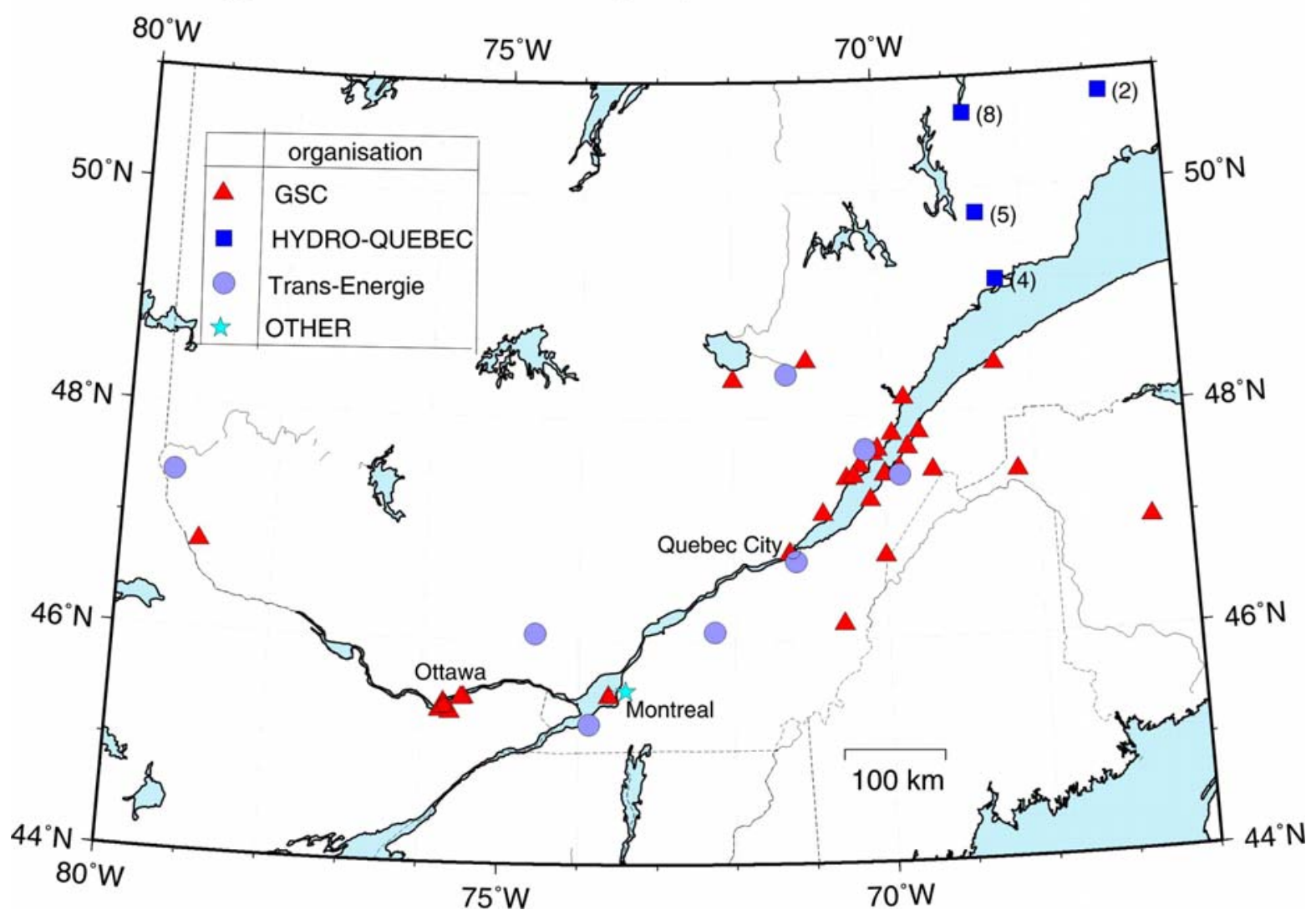

Figure 4. Strong motion seismographs in eastern Canada. Numbers in parenthesis indicate the total number of instruments at the site.

\section{Hydro-Québec I Trans-Energie}

Hydro-Québec and Trans-Energie have instruments installed at key hydroelectric dams and transformer sub-stations (Figure 4) as a part of their overall permanent seismic monitoring program that includes a network of 12 seismographs telemetered to Ottawa in real-time. The former provide free field and structural response for the generating systems along the Manicouagan River, while the response of the overburden at transformer stations, one of which was seriously damaged during the 1988 Saguenay earthquake, is covered by the latter. Most of the 27 sites are fitted with Kinemetrics SSA-1's (1 or 2g) or $2 \mathrm{~g}$ ETNA's, while one dam remains instrumented with 8 analogue SMA-1 $1 \mathrm{~g}$ units. The 8 Trans-Energie (Hydro-Québec) instruments have trigger levels ranging from $0.05 \% \mathrm{~g}$ to $0.2 \% \mathrm{~g}$.

The electric substations network is automated with all instruments connected to a central computer. The instrument status is checked remotely and regularly. The recordings are analyzed in Montreal at the Trans-Energie office. Immediately after any event, the automated system generates a summary report (accelerograms and maximum accelerations in the 3 directions) for each of the triggered instruments. A short time later, a second report is produced containing accelerations, velocity and displacement time history, and the corresponding response spectrum. Future plans of Trans-Energie include adding additional strong motion instruments to provide redundancy and more reliable network operation. 


\section{Ontario Power Generation}

A 10-sensor strong ground motion system from Terra Technologies using mechanical FBAs operated at the Pickering Nuclear Power plant until about 2002, but is currently not operating. It recorded ground motions from two nearby magnitude 3 earthquakes on 19991126 and 20000524. An 8-sensor 3component strong ground motion system from Syscom (http://www.syscom.ch/) has operated at the Darlington Nuclear Power Plant since January 2006. It includes one 'free-field' sensor outside of the immediate power plant. Current trigger level on all sensors is $1 \% \mathrm{~g}$ but some will be lowered to $0.5 \% \mathrm{~g}$. To date, there have been no earthquake triggers.

\section{Other}

Gaz Metropolitian Inc. and New Brunswick Power both have one free field digital accelerograph installed at their respective facilities (LNG plant in Montreal and the Point Lepreau nuclear generating station). The Institute for Research in Construction of the National Research Council Canada operates three seismograph systems on Parliament Hill in Ottawa for Public Works and Government Services Canada. The systems, which comprise five SSA-2s and six K2s (Kinemetrics), have trigger levels set mainly at $0.5 \% \mathrm{~g}$. Since being deployed in the late 1990's, they have recorded ground and building tower responses to several earthquakes.

Table 1. Strong motion instruments deployed in Canada (as of Jan. 2007).

\begin{tabular}{|c|c|c|c|}
\hline Owner & Analogue & Digital & Total \\
\hline GSC West & - & 97 & 97 \\
\hline BC Hydro & 28 & 11 & 39 \\
\hline BCTransmission Corp. & - & 23 & 23 \\
\hline $\mathrm{BC} \mathrm{MoT}$ & - & 17 & 17 \\
\hline Other West ${ }^{*}$ & - & 2 & 2 \\
\hline GSC East & 1 & 36 & 37 \\
\hline Hydro-Québec & 8 & 19 & 27 \\
\hline Other East $^{*}$ & - & 13 & 13 \\
\hline
\end{tabular}

*This number may not be complete as we have not surveyed all potential owners.

\section{Recent Accelerograms}

Since the last review of strong motion networks in Canada by Rogers et al. in 1999, 12 earthquakes have triggered strong motion instruments providing significant data sets in both western and eastern Canada (see Table 2). The deployment of 97 IA stations in southwest BC by the GSC since 2002, is now resulting in much larger datasets than in the past. Most of the higher amplitude accelerograms have been processed by the Geological Survey of Canada following U.S. Geological Survey procedures (e.g. Converse, 1995) and released as Open Files. Here, we briefly summarize the more significant data sets, and some analysis results.

In western Canada there have been 9 earthquakes recorded on the strong motion network since 1999 (Table 2). In all cases, the "strong motion" recordings are at shaking levels less than $6 \% \mathrm{~g}$. The Mw=6.8 Nisqually earthquake of 28 February, 2001 produced 96 strong motion records in southwest BC (distances of $150-300 \mathrm{~km}$ and shaking levels of up to $3.5 \% \mathrm{~g}$ ). For details of this combined GSC, BC Hydro dataset, see Cassidy et al. (2003). A thorough analysis of these data, including comparisons with local geology and felt effects, is provided in Molnar et al. (2004a) and Molnar et al. (2004b). A study comparing the Nisqually earthquake recordings with ambient noise measurements to estimate seismic site response (Molnar and Cassidy, 2006) showed excellent agreement between these two datasets in the Victoria, BC region. 
The largest strong motion data sets were obtained for the offshore Vancouver Island earthquakes of July 15, 2004 and July 19, 2004. A total of 108, and 132 records (respectively) were obtained at distances of $90-300 \mathrm{~km}$. A peak horizontal acceleration of $0.6 \% \mathrm{~g}$ was recorded for the $\mathrm{Mw}=5.9$ event of July 15 , and a peak acceleration of $1.4 \% \mathrm{~g}$ was recorded for the $M w=6.4$ event of July 19. This data set, comprised of GSC IA data as well as BC Hydro and BCTC data, is described in Molnar et al. (2006a).

Recordings of the 29 November $2002 \mathrm{M}=3.9$ Georgia Strait earthquake (18 records, with peak acceleration of $0.4 \% \mathrm{~g}$ ) and the 25 April $2003 \mathrm{M}=4.2$ Olympic Peninsula, Washington State, earthquake (78 records, peak acceleration of $0.8 \% \mathrm{~g}$ ) are documented in Molnar et al. (2006b).

During 2006, two widely felt earthquakes near Victoria BC produced significant data sets (Cassidy et al., in preparation). The $\mathrm{ML}=3.6$ earthquake of 15 January 2006 produced 102 records, with a peak acceleration of $1.5 \% \mathrm{~g}$, and the 4 July $2006 \mathrm{Mw}=4.0$ event produced 72 records with a maximum peak acceleration of $3.9 \% \mathrm{~g}$. These events were recorded to distances of $83 \mathrm{~km}$ and $42 \mathrm{~km}$, respectively. Two other earthquakes near Victoria, recorded only on BCH and BCTC instruments (they occurred prior to the GSC IA network deployment) are the 11 December $1999 \mathrm{Mw}=4.9$ event and the 20 September 2002 $\mathrm{M}=4.3$ event. The 1999 event yielded a total of 12 accelerograms with a peak acceleration of $5.4 \% \mathrm{~g}$, and the 2002 event yielded 18 records with a peak acceleration of $3.4 \% \mathrm{~g}$.

In eastern Canada 3 earthquakes have been recorded on the strong motion networks (Table 2). The Au Sable Forks, New York earthquake of 20 April 2002 produced 18 accelerograms in Ottawa, 12 of the magnitude $M_{W} 5.0$ mainshock and 6 of a M4.1 aftershock (Al-Khoubbi and Adams, 2004). The $M_{W} 4.7$ Rivière-du-Loup (Grand-Portage) earthquake of 6 March 2005 produced 9 GSC accelerograms, as well as recordings on the Hydro-Quebec network. Two of the latter recordings at epicentral distances of 20-25 $\mathrm{km}$ were as large as $15 \% \mathrm{~g}$. The $\mathrm{M}_{\mathrm{W}} 4.0$ Thurso earthquake of 25 February 2006 produced 21 accelerograms (Adams, 2007, in prep) with soil-amplified peak accelerations up to $3 \%$ g. Analysis of these data will provide new information on site response effects in the Ottawa and St. Lawrence Valley regions.

Table 2. Recent significant data sets from strong motion seismographs in Canada.

\begin{tabular}{|c|c|c|c|c|}
\hline Earthquake & Date & Location (Lat, Lon) & Magnitude & No. Records \\
\hline Victoria & $99 / 12 / 11$ & $48.52 \mathrm{~N}, 123.27 \mathrm{~W}$ & $M_{w} 4.9$ & 12 \\
\hline Nisqually, WA & $01 / 02 / 28$ & $47.15 \mathrm{~N}, 122.71 \mathrm{~W}$ & $M_{W} 6.8$ & 96 \\
\hline Au Sable, NY & $02 / 04 / 20$ & $44.53 \mathrm{~N}, 73.73 \mathrm{~W}$ & $M_{w} 5.0$ & $24^{*}$ \\
\hline Victoria & $02 / 09 / 20$ & $48.49 \mathrm{~N}, 123.15 \mathrm{~W}$ & $M_{w} 4.3$ & 18 \\
\hline Georgia Strait & $02 / 11 / 29$ & $48.92 \mathrm{~N}, 123.06 \mathrm{~W}$ & $M_{L} 3.4$ & 18 \\
\hline $\begin{array}{c}\text { Olympic } \\
\text { Peninsula, WA. }\end{array}$ & $03 / 04 / 25$ & $47.67 \mathrm{~N}, 123.25 \mathrm{~W}$ & $M_{W} 4.6$ & 78 \\
\hline $\begin{array}{c}\text { Offshore } \\
\text { Vancouver Isle. }\end{array}$ & 04/07/15 & $49.52 \mathrm{~N}, 127.24 \mathrm{~W}$ & $M_{W} 5.8$ & 108 \\
\hline $\begin{array}{c}\text { Offshore } \\
\text { Vancouver Isle. }\end{array}$ & 04/07/19 & $49.47 \mathrm{~N}, 127.25 \mathrm{~W}$ & $M_{W} 6.4$ & 132 \\
\hline Rivière-du-Loup & 05/03/06 & $47.75 \mathrm{~N}, 69.73 \mathrm{~W}$ & $M_{w} 4.7$ & 15 \\
\hline Victoria & 06/01/15 & $48.57 \mathrm{~N}, 123.53 \mathrm{~W}$ & $M_{L} 3.6$ & 102 \\
\hline Thurso & $06 / 02 / 25$ & $45.66 \mathrm{~N}, 75.24 \mathrm{~W}$ & $M_{w} 4.0$ & 21 \\
\hline Victoria & 06/07/04 & $48.33 \mathrm{~N}, 123.20 \mathrm{~W}$ & $M_{w} 4.0$ & 72 \\
\hline
\end{tabular}

*Includes recordings of an aftershock 


\section{Conclusions}

During the past seven years the number of strong motion seismographs in Canada has nearly doubled to approximately 250. Most of these instruments are located in the earthquake prone regions of British Columbia and Quebec, and almost all are in networks operated by the Geological Survey of Canada, British Columbia Hydro, British Columbia Transmission Corporation, Hydro-Québec, and the British Columbia Ministry of Transportation and Highways. In contrast to just 7 years ago, the vast majority of instruments are now digital (85\%) and about half have real-time communication capabilities. Most of the GSC instruments are in small buildings or surface huts in order to be as close to free-field conditions as possible. BC Hydro, BC Transmission Corporation, and Hydro-Québec have deployed instruments on and near major dams and at strategic electrical substations in southwestern British Columbia and Québec.

During the period 1999-2006, nearly 700 accelerograms have been recorded across Canada, most in southwest BC, and most by the new real-time IA network. Almost all of these records represent weak motion $(<5 \% \mathrm{~g})$. These data sets have been used to better estimate ground motion attenuation and earthquake source characteristics and frequency content. The low-level recordings in southwest British Columbia have provided important new information on the variability of the seismic response on the soft soils of the Fraser River Delta.

\section{Acknowledgments}

We thank BC Gas, Don Duchesne of Public Works and Government Services Canada, Gaz Metropolitian Inc., and New Brunswick Power for sharing data and providing information on their strong motion seismograph installations. Many thanks to Dieter Weichert for reviewing this manuscript. GSC contribution number 20060507.

\section{References}

Al-Khoubbi, I. and Adams, J., 2004. Local site effects in Ottawa, Canada - First results from a strong motion network; in, Proceedings of the 13th World Conference on Earthquake Engineering, Paper No. 2504.

Cassidy, J.F., Molnar, S., Rogers, G.C., Mulder, T., and Little, T.E., 2003. Canadian strong ground motion recordings of the 28 February, $2001 \mathrm{M}=6.8$ Nisqually (Seattle-Olympia) Washington, Earthquake, Geological Survey of Canada, Open File 1737, 91 p.

Converse, A., 1995. BAP: Basic Strong-Motion Accelerogram Processing Software package, 20 April 1995 PC-version, USGS Open File report 92-296A.

Latendresse, V. and Ventura, C.E., 1997. Strong Motion Instrumentation Reports, Queensborough Bridge, Massey Tunnel, and French Creek Bridge, prepared for B.C. Ministry of Transportation and Highways Engineering Branch, by Department of Civil Engineering, University of British Columbia, Vancouver, B.C., 147pp.

Milne, W.G. and Rogers, G.C., 1971. Earthquake Engineering Research at Victoria Geophysical Observatory. Proceedings of First Canadian Conference on Earthquake Engineering, University of B.C., Vancouver, B.C., 27-37.

Molnar, S., Cassidy, J.F. and S.E. Dosso, 2004a. Site response in Victoria, BC from spectral ratios and 1D modeling, Bulletin of the Seismological Society of America, 94, 1109-1124. 
Molnar, S., Cassidy, J.F. and S.E. Dosso, 2004b. Comparing intensity variation of the 2001 Nisqually earthquake to geology in Victoria, British Columbia, Bulletin of the Seismological Society of America, 94, 2229-2238.

Molnar, S., and Cassidy, J.F., 2006. A comparison of site response techniques using earthquakes and microtremors, Earthquake Spectra, 22, 169-188.

Molnar, S., Rosenberger, A., Cassidy, J. F., Rogers, G. C., Ristau, J., 2006a. Digital accelerograph recordings of the July 15 and 19, 2004 earthquakes, west of Vancouver Island; Geological Survey of Canada, Open File 5010, 76 p.

Molnar, S., Rosenberger, A., Cassidy, J. F., Rogers, G. C., 2006b. Internet accelerograph recordings of low-level earthquakes in southwestern British Columbia from 2002 to 2003; Geological Survey of Canada, Open File 5266, 2006; 21 p.

Rainer, J.H. and Dascal, O., 1991. Behaviour of instrumented Hydro-Québec dams during the Saguenay earthquake. Proceedings, Canadian Dam Safety Conference, Whistler, B.C., 189-202.

Rainer, J.H. and Luctar, E.C., 1983. The eastern Canadian Strong Motion seismograph network. Proceedings of the Fourth Canadian Conference on Earthquake Engineering, Vancouver, B.C., 519-528.

Rogers, G.C., 1976. A survey of the Canadian strong motion seismograph network. Canadian Geotechnical Journal, Vol. 13, 78-85.

Rogers, G. C., Cassidy, J. F., Munro, P. S., Little, T. E., 1999. Strong motion seismograph networks in Canada; in, Proceedings of the 8th Canadian Conference on Earthquake Engineering, 71-76.

Rosenberger, A., Rogers, G. C., Cassidy, J. F., 2007. The new real-time reporting strong motion seismograph network in southwest BC: More strong motion instruments for less money; in, Proceedings of the 9th Canadian Conference on Earthquake Engineering.

Weichert, D.H., and Munro, P.S., 1987. Canadian strong motion seismograph networks. Fifth Canadian Conference on Earthquake Engineering, Ottawa, Ont., 647-654. 